\title{
SECTION E \\ MARKET-ORIENTED HEALTH CARE REFORMS: TRENDS AND FUTURE OPTIONS
}

\author{
WYNAND P. M. M. VAN DE VEN \\ Department of Health Care Policy and Management, Erasmus University Rotterdam. P.O. Box 1738. \\ 3000 DR Rotterdam. The Netherlands
}

\begin{abstract}
In many (predominantly) publicly financed health care systems market-oriented health care reforms are being implemented or have been proposed. The purpose of these reforms is to make resource allocation in health care more efficient, more innovative and more responsive to consumers preferences while maintaining equity. At the same time, the advances in technology result in a divergence of consumers' preferences with respect to health care and urge society to (re)think about the meaning of the solidarity principle in health care. In this paper we indicate some international trends in health care reforms and explore some potential future options. From an international perspective we can observe a trend towards universal mandatory health insurance, contracts between third-party purchasers and the providers of care, competition among providers of care and a strengthening of primary care. These trends can be expected to continue. A more controversial issue is whether there should also be competition among the third-party purchasers and whether in the long run there will occur a convergence towards some "ideal" model. Although regulated competition in health care can be expected to yield more value for money, it might yield both more efficiency and higher total costs. It has been argued that equity can be maintained in a competitive health care system if we interpret equity as "equal access to cost-effective care within a reasonable period of time". Because the effectiveness of care has to be considered in relation to the medical indication and the condition of the patient, the responsibility for cost-effective care rests primarily with the providers of care. Guidelines and protocols should be developed by the profession and sustained by financial incentives embedded in contracts. It has been argued that the third-party purchasers could start to concentrate on the contracts with the primary care physicians. Contracts with other providers could then be a natural complement to these contracts. Coordinated-care contracts between the third-party purchasers and the consumer of care could provide the consumer with monetary incentives to go to efficient providers. A consumer choice of insurance contract could give the consumer an opportunity to make important choices in health care. However, each society has to make its own choices about what care should be available to everybody independent of an individual's purchasing power. Copyright 1996 Elsevier Science Ltd
\end{abstract}

Key words-health care reforms, regulated competition, cost-effectiveness, choices in health care

\section{INTRODUCTION}

In many (predominantly) publicly financed health care systems market-oriented health care reforms are being implemented or have been proposed. The purpose of these reforms is to make resource allocation in health care more efficient, more innovative and more responsive to consumers' preferences while maintaining equity. At the same time the advances in medical technology result in a divergence of consumers' opinions about the desirability of certain types of care, such as abortion. in vitro fertilization, treatments with a low probability of success and a high probability of complications, iatrogenesis, alternative health care (e.g. homeopathic care, acupuncture) and euthanasia. Furthermore, advances in medical technology urge society to (re)think about the meaning of the solidarity principle in health care, which usually implics that every citizen contributes according to "ability to pay" and receives care according to "ability to benefit". But does the solidarity principle also imply that everyone has access to all health care with any positive marginal effectiveness independent of the costs? And if not, which presumably is the case because society cannot afford it, what health services should be available to everybody independent of one's purchasing power? The challenge, therefore, is not only to find new structures of organizing and financing health care, but also to find, within these new structures. a new balance between equity and efficiency. The purpose of this paper is to indicate some international trends in health care reforms that can be observed and, extrapolating these trends, to explore potential future options.

\section{TRENDS IN HEALTH CARE REFORMS}

At first sight the health carc reforms in many countries seem very different from each other: all 
reforms contain elements related to the countryspecific aspects of a health care system; in many countries (e.g. Belgium, Germany and Sweden) the "reforms" consist of a series of incremental steps without a clear "blueprint"; and there is a lot of misleading ideological rhetoric. However, when looking at the concrete changes in the structure, organization and financing of health care systems during the 1980 s and early 1990 s, the following trends can be observed [1-6].

\section{Mandatory health insurance}

A trend to universal, or near universal, mandatory health insurance arrangements can be observed. In the 1980s universal health insurance was implemented in Australia, Greece, Italy, Portugal and Spain; and in the 1990s in Ireland, Israel and Switzerland. Extension of the mandatory health insurance system is under discussion in the Netherlands, Turkey and the United States. Mandatory health insurance can be financed in different ways: by general taxes, earmarked taxes, national or local taxes, social insurance premiums or other (income-related) contributions. No country is reducing the number of persons covered by mandatory health insurance.

\section{Public contract model}

There are some signs of convergence on the so-called public contract model, ${ }^{*}$ i.e. a public financing of health care combined with a system of contracts between providers and third-party purchasers of care (e.g. Regional Health Authorities or insurers). In countries with a "classical" National Health Service (e.g. Finland, New Zealand, Russia, Sweden, the United Kingdom and some Southern and Eastern European countries) this trend reflects a move away from a vertically integrated system towards a separation of the purchaser and the providers of care, who then have to conclude contracts with each other. In a "classical" National Health Service the Regional Health Authorities (or County Councils) are responsible for both purchasing and providing care. The combination of being both a monopsonistic buyer and a monopolistic seller of care involves the danger of provider domination ("provider capture"). As a result, these health care systems may have become more provider-oriented than consumer-oriented, and consequently (the incentives for) efficiency and responsiveness are weakened. Therefore, a strong case can be made for the creation of organizations whose only responsibility is to be a clear defender of the consumers' interests and who have incentives to do so. Creation of this kind of "consumer interest organization" can be achieved by a separation of the purchasing function and the provider function. In countries where insurers or sickness funds tradition-

*For the introduction of this terminology, see [1]. ally reimbursed patients in cash for the cost of their medical care (Belgium, France, and partly the Netherlands) we see a trend towards direct payment of the providers by the insurer or sickness fund, based on contracts between them. This gives the "remote" third-party payer the opportunity to become a prudent buyer of care on behalf of its members.

\section{Consumer choice of provider}

A third trend that can be observed is an increase in the consumers' freedom to choose a provider. This trend can be observed, for example, in Denmark, Finland, the United Kingdom and Sweden. A consumer choice of provider may lead to consumerled competition among the providers of care.

\section{Competition among providers}

A trend towards competition among providers of care can be observed in many countries: Germany, Israel, the Netherlands, New Zealand, Sweden, the United Kingdom, Russia and other Eastern European countries. The trend is not towards a free market, but towards regulated competition. The emphasis of government regulation is switching away from command-and-control measures towards procompetition policies. Third-party purchasers negotiate with the providers about the quality, volume and price of care. The results of the negotiations are reflected in the contracts between the purchasers and providers of care. Selective contracting by third-party purchasers is expected to yield competition among providers.

\section{Competition among third-party purchasers}

A more controversial issue in market-oriented health care reforms is the question whether or not there should also be competition among the third-party purchasers of care. In Belgium, Germany, Israel, the Netherlands, Russia and Switzerland the choice has been made in favour of a competitive market for third-party purchasing. The United Kingdom and Sweden chose for a regional monopoly of the third-party purchaser. In New Zealand, Portugal and Italy the option to opt-out the public system and to choose an alternative "third-party purchaser" instead of the Regional Health Authority has been seriously discussed but was ultimately rejected.

\section{Strengthening primary care}

In many countries a strengthening of the position of primary care providers can be observed: Finland, Germany, Greece, Italy, the Netherlands, Norway, Sweden ("Family Doctor Reform", 1994), the United Kingdom and the U.S. (managed care plans). General practitioners (GPs) are assumed to function as a gatekeeper to second-line care such as specialist care, prescription drugs and hospital care. A further step is to give the primary care providers financial 
responsibility for (a part of) the costs of the follow-up care provided by others to their patients. Since 1991 GPs in the United Kingdom can voluntarily become a GP-fundholder. In 1996 about $40 \%$ of the population in the United Kingdom has a fundholding GP, i.e. a GP who bears the financial responsibility for purchasing part of the second-line care. Surpluses may be invested in the GPs' practices. Since 1994 the regional associations of ambulatory physicians in Germany receive a budget for their own services plus prescription drugs. Deficits in the drug budget have to be compensated by a reduction of the fee for the physician services. In Finland about 200 primary health care centres purchase all second-line care needed for a given population. Experiments with fundholding primary care centres have been held in Russia (Leningrad and Kuzbass), Sweden (Bohus and Dalarna), Israel (Negev) and Switzerland. The European forms of "budgetholding primary care centres" bear a resemblance to the "shared risk pools" as applied in health maintenance organizations (HMOs) in the U.S. [7].

\section{Choices in health care}

Finally, more and more countries are realizing that society can no longer afford to make all new medical technologies available to everyone. Therefore, there is an increasing need in developed countries to make choices about what health services should be available to everybody independent of one's purchasing power. Each country probably has its own publicly debated, painful cases of denying an expensive high-tech medical treatment to an identifiable patient, like the case of Coby Howard (Oregon, 1987) and Child B. (the United Kingdom, 1995). Making these choices in health care (sometimes indicated as "rationing") can be done either by excluding certain medical treatments from the mandatory health insurance coverage and/or by the use of protocols and guidelines. The first strategy has been explicitly applied in Oregon [8]. In other countries where choices in health care are explicitly debated, like the Netherlands [9], New Zealand [10], Sweden [11] and the United Kingdom [12], there exists a preference for the second strategy. Given the expected developments in medical technology, "choices in health care" may become the major issue in health care reform in the next decade.

\section{FUTURE OPTIONS}

The above-mentioned trends indicate a global direction of the market-oriented health care reforms in many countries. Most of these reforms are in an initial stage. A full realization can take a decade or longer. An interesting question therefore is what future trends can be expected. In this section we will extrapolate the current trends and speculate on some future options.

\section{A prime role for primary care}

One of the current trends is a strengthening of primary care and the role of primary care physicians. In some countries (e.g. Denmark, the Netherlands and the United Kingdom) it has been quite usual for already a long period of time to have a personal GP as a family practitioner who is assumed to authorize and coordinate all needed care. In order to be eligible for specialist care, one generally has to be referred by one's GP. There are several advantages of having a GP as a personal physician who authorizes and coordinates care, such as:

(1) There is a high chance-much higher than in the case of self-referral-that the patient is referred at the right time directly to the right specialist;

(2) GPs as well-informed agents for their patients may evaluate the quality of care delivered by other providers and can be helpful in selecting good quality second-line providers;

(3) GPs may coordinate the drugs prescribed by other physicians, which may reduce adverse drug effects;

(4) It may lead to more personal care for the patient because of the longstanding personal relation between the GP, the patient and the patient's family; and

(5) It may also lead to a close cooperation between the GP and specialists, which may ultimately result in both better quality and lower costs due to: better cooperation and mutual understanding between GPs and specialists; the specialist "retraining" the GP and the GP informing the specialist about the patient's personal circumstances, medical history and other relevant background; common protocols and procedures for medical treatment and referrals; better referrals, i.e. with a specific purpose in mind and carefully selected questions from the GP to the specialist; less unnecessary treatments and diagnostic tests by specialists in hospitals; and shorter specialist treatments because the specialist is aware of the GP's capabilities.

An often mentioned disadvantage of the GP-gatekeeper model is the restricted entry to specialist care. Nevertheless, because having a GP as a personal physician who authorizes and coordinates care can help to improve the efficiency in health care-which is one of the goals of market-oriented health care reforms-the trend towards a strengthening of primary care can be expected to continue.

\section{Contracts}

A second trend that can be expected to continue for the next decade in many countries is the trend towards contracts between third-party purchasers and the providers of care. Compared with the 
reimbursement model, where an individual consumer acts as the purchaser at the time that he needs care, the contract model, where a third-party purchaser (e.g. a Regional Health Authority, a County Council, a sickness fund or an insurer) acts as a prudent buyer of care on behalf of its members, has the following advantages:

- the third-party purchaser can reduce the information asymmetry between purchaser and provider by employing or hiring medical advisors;

- the third-party purchaser can exert his market power while negotiating with the providers of care;

- the third-party purchaser can collect and compare performance indicators of the providers and thereby stimulate quality assessment;

- the third-party purchaser, who contracts with providers of different types of care, can stimulate via the contracts the coordination of these types of care; and

- the third-party purchaser can develop a longterm contractual relationship with providers and thereby stimulate the planning of health care facilities.

Compared with a "classical" National Health Service, the contract model has the advantage that it can improve the flexibility of the health care system and make the system less provider-dominated and more consumer-oriented.

Despite the relatively high transaction costs of the contract model, at least for the next decade, the trend towards contracts between third-party purchasers and providers of care can be expected to continue.

Contracts between purchasers and primary care physicians. A logical way for third-party purchasers (Regional Health Authorities, County Councils, sickness funds or insurers) to build up a network of contractual arrangements is to follow the natural way the patient enters the health care system. Therefore, third-party purchasers could start to concentrate on the contracts with the primary care physicians. Contracts with other providers (specialist care and institutional care) could then be a natural complement to these contracts and in fact could be supportive to the conditions agreed upon in the contracts between the purchaser and the primary care physicians. Primary care physicians could select the specialists and the hospitals with which they prefer to cooperate and to which they prefer to refer their patients. In this way the knowledge and experience of the GPs and their professional views about how to provide good quality care and how to organize health care efficiently can be combined with the power of the purchaser to contract selectively with specialists and hospitals. Especially when the GPs prefer a certain practice style (e.g. certain guidelines or protocols) in their cooperation with other providers, the contracts between the purchaser and these other providers can be a powerful tool to achieve the desired practice style.

In applying the strategy of giving a prime role to primary care, the purchasers may run up against a shortage of GPs. In that case, they could make it (financially) attractive for hospital-based specialists, e.g. an internist, a gynaecologist or a paediatrician, to come to work in a large primary care centre. This could yield all the above-mentioned advantages of a close cooperation between GPs and specialists. They could function partly as the personal primary care physician who coordinates all the care for specific patients, like diabetics, women between 15 and 45 years of age, and young children; and they could partly function as a consultant to the other primary care physicians within the centre. In large primary care centres these "primary care specialists" could work on a full-time basis, while in the case of smaller centres they could combine part-time working in the primary care centre with part-time working in the hospital.

As prudent buyers of care on behalf of their members, the purchasers can be expected to conclude contracts with primary care physicians that contain elements for improving efficiency, responsiveness and coordination of care. Responsiveness, in terms of convenient locations, opening hours, waiting lists, waiting times in the physician's office and attainability by telephone, is probably quite straightforward. With respect to efficiency and coordination of care, things are more complicated. There appears to be a large variation in practice styles among physicians [13]. Mokkink [14] found that different practice styles of Dutch GPs have considerable consequences in terms of quality of care and costs. He distinguished four styles of practice.

The "integrated work style" involves a GP who looks at the total picture of a patient-cultural, social and psychological-and develops a strong rapport with the patient. These physicians refer to specialists less frequently, prescribe fewer drugs, have fewer unnecessary diagnostic treatments, and are less aggressive in their use of medical technologies. The reduction in their referral pattern is solely due to a substantial reduction of referrals for non-severe, self-limiting diseases. Due to their style, these physicians have lower iatrogenic disease rates and lower costs (approximately 25-35\%) than physicians with other work styles.

Having identified GPs with such a desired practice style, it would be very attractive for purchasers to selectively contract only with these GPs. However, these GPs probably will form a minority (about one-quarter in Mokkink's study), so by following this strategy the purchasers would not contract enough primary care for their members. Therefore, it is also necessary to contract GPs with less desirable working styles and change their styles into the desired direction. For example, a purchaser can reward GPs 
for going to continuing education courses, refresher courses, etc. A purchaser could invest in setting up a medical monitoring system that provides physicians with relevant information about their working style and their performance. In addition, the purchaser could contract with a GP who is well respected within the GP community to provide feedback and clinical direction to other GPs [15]. It appears that physicians' practice style can be changed by providing the physicians with relevant information about their behaviour $[16,17]$. In concert, the purchasers and the GPs should come to a remuneration system that rewards good quality and desired practice style [18]. They should determine good outcome measures [19], as well as measurable parameters of good quality care and desired working style. Subsequently, the primary care physicians' remuneration should be such that the physicians' income is higher the closer the ideal parameter values are approached. Although most physicians have idealistic motives for delivering the best quality care, it would be naive to assume that these motives are the only determinant of their practice style.

Several examples can be given of how the method of remuneration influences GPs' behaviour. After replacing the GPs' full capitation scheme by a mixed capitation and fee-for-service system in Copenhagen (1985), the rates of examinations and treatments that attracted specific additional remuneration rose significantly compared with a control group for which the remuneration system remained unchanged: diagnostic services rose by $48 \%$ and curative services by $69 \%$. The referral rates to secondary specialist care fell by $21 \%$ and the hospital referral rates fell by $34 \%$, both as compared to the control group [20]. Another study focused on the effects of adding a productivity bonus (related to the gross monthly charges generated by the physicians) to the flat rate fee per hour of primary care physicians (Boston, 1985). As a result of the new financial incentives, the physicians increased the number of laboratory tests performed per patient visit by $23 \%$ and the number of X-ray films per visit by $16 \%$. The total charges per month, adjusted for inflation, grew by $20 \%$, mostly as a result of a $12 \%$ increase in the average number of patient visits per month [21]. In a third study it was found that the use of capitation or salaries as a way of reimbursing primary care physicians was associated with $7 \%$ and $13 \%$, respectively, lower rates of hospitalization than the use of fee-forservice payment [22]. A fourth study found that bonus payments, dependent on prescription rates, referral rates and hospitalization rates, on top of the GPs' capitation, resulted in approximately $10 \%$ lower utilization of services (Tilburg, 1984-1988) [23].

The lesson to be learned form these studies is that financial incentives matter (although not all important incentives are financial) and that it is important to structure the method of primary care physicians' remuneration in such a way that desired practice styles are rewarded. This can be done by some bonus elements, with the bonus(es) related, for example, to prescription drugs, referral rates, inpatient care and overall per capita costs, with all figures adjusted for age, gender and health status. Note that there is an essential difference between such a remuneration scheme and the GP fundholding scheme in the United Kingdom. The GP-fundholders receive a budget from which they have to purchase other care, like hospital care, specialist care or prescription drugs. In the case of performance-related bonuses, it is the third-party purchaser who contracts the GPs and who also purchases the second-line care. Appropriate financial incentives (bonuses) for the primary care physicians, who are responsible for the coordination and pre-authorization of secondary care, then stimulate desired practice styles and desired outcomes.

Contracts between purchasers and second-line providers. All kinds of contractual arrangements between the purchaser and the second-line providers may emerge. The contracts may deal with matters like quality of care, volume, responsiveness, waiting lists, available capacity, costs and cooperation with primary care physicians. The purchaser may contract with different (groups of) providers: with individual specialists, (networks of) groups of specialists or medical staff; with individual hospitals or networks of hospitals; or with "provider organizations", consisting of combinations of the above-mentioned entities, which may be mutually linked to each other via contractual arrangements.

As far as the financial aspects of the contracts are concerned, one can think of all kinds of methods of reimbursement. Hospital payment could consist of a prospectively determined budget, case-payments or per diem payments. Individual physicians could be salaried, paid a fixed amount per period per person (capitation), or they could be paid a fee for each item of service. Groups of physicians could be paid a predetermined capitated amount, while the group pays the individual physicians in a self-determined way. All kinds of financial risk sharing between the purchaser, hospitals and (groups of) physicians can be thought of.

Via the contracts the purchasers can stimulate many kinds of utilization management techniques to control unnecessary or unnecessarily expensive use of care. These strategies can incorporate a variety of tactics. The setting of care can be relocated from a high-cost location (a hospital) to a low-cost location (a home or nursing facility) through discharge planning. Prior authorization for inpatient care and second surgical opinions may improve efficiency. Outpatient care can be substituted for inpatient care, and a greater emphasis can be placed on primary care. Improved utilization of existing facilities (by evening or weekend operation, or by closing excess capacity) can result in higher efficiency. 
Rationalization of labour practices, involving work force reallocations, can also reduce costs.

In order to be able to conclude contracts and implement a variety of utilization management programmes, the presence of well-developed management information systems is a prerequisite [24]. The initiative for developing these information systems could be taken by large provider-organizations, by a network or group of providers, or by the purchaser. For example, when a purchaser contracts with individual primary care physicians or relatively small primary care centres, these providers cannot afford to buy a sophisticated management information system. In that case the purchaser could do it and could be supportive of the primary care physicians not only in making physicians' profiles and utilization management, but also in selecting efficient hospitals.

Contracts between purchasers and consumers of care. In countries with a "classical" Natural Health Service, the way that budgets were allocated to hospitals did not contain incentives to attract more patients because "the money did not follow the patients". An important aspect of the reform in, for example, New Zealand, Sweden and the United Kingdom, therefore, is that "the money follows the patient". This principle is assumed to be an important incentive for the providers of care to accept contracts that contain incentives for efficiency, responsiveness and coordination of care. As far as responsiveness is concerned, this reasoning makes sense: because consumers like responsiveness, they will choose providers of care who are responsive. But with respect to the incentives for efficiency and coordination of care, it need not work that way. Physicians often put forward that their patients urge them to prescribe useless drugs (e.g. the chronic use of sleeping pills or antibiotics for a simple cold caused by a virus) or unnecessarily refer them to a specialist. According to physicians, the patients often urge them to perform all kinds of cost-ineffective diagnostic procedures. If individual consumers do not have any personal interest in receiving efficient and coordinated care, while the money follows the patient, the efficient providers might have a rough time in attracting enough patients! Indeed, if patients, for whatever reasons, prefer inefficient and uncoordinated care to efficient and coordinated care--keeping responsiveness equal-both the patients and the money will go to providers of inefficient and uncoordinated care.

Therefore, it makes sense to give the consumer, analogously to the natural incentive to go to responsive providers, a monetary incentive to go to efficient providers and agree with their practice style (e.g. guidelines and protocols). So a natural coping-stone of the contractual arrangements between the purchaser and the providers is a contract between the purchaser and the consumers of care. In return for a monetary reward these contracts might specify some conditions for receiving care. These conditions could relate to who delivers the care (e.g. only those who are indicated on a list of "preferred" providers), where the care is delivered (e.g. in hospitals with which the chosen primary care physician cooperates) and the acceptance of the coordination and authorization by some physician or provider organization (e.g. referral; secondary surgical opinion; pre-authorization of hospitalization). Of course, there have to be exclusions for emergency cases, for out-of-area cases, and probably also for some forms of very highly specialized care. In this way different kinds of coordinated-care contracts hetween the third-party purchaser and the consumers of care may arise. Preferably, these contracts should be attuned to the contracts between the purchaser and the providers of care. In order to be sure that the purchasers fulfil their duty to contract enough care according to the needs of their members and to guarantee that the consumer has enough access to good care according to his needs, one might think of establishing a National Board on Certification, which has to certify all coordinated-care contracts.

As far as the monetary rewards are concerned, one can think of reduced or no copayments, or a premium or $\operatorname{tax}$ reduction. The rationale behind these monetary incentives is that coordinated, efficient care and a totally free choice of provider cannot go together. However, it is possible to give the consumer a free choice between coordinated, efficient care for a reasonable price and uncoordinated, inefficient care for a high price. Ultimately, the choice is the consumer's.

\section{Convergence}

A third trend that can be expected to continue in many countries is the shift of government regulation from command-and-control measures towards procompetition policies. An example of such a policy is to allow the third-party purchasers to selectively contract with providers of care. This will yield competition among providers. The trend towards competition among providers of care can be expected to continue. However, a more controversial issue is whether or not there will also be competition among the third-party purchasers of care. Several arguments can be mentioned in the discussion about the choice between a competitive model and a monopsonistic model (i.e. a monopolistic market for third-party purchasing in combination with a competitive provider market).

An argument in favour of the monopsonistic model is that a monopsonistic third-party purchaser can exert maximum buyer power to obtain the best medical care at the lowest prices, especially when the provider market is highly competitive. Another argument in favour of the monopsonistic model is that transaction costs are likely to be lower than in a competitive market, since providers have to conclude a contract with a single purchaser only. 
Moreover, the costs of advertising will be lower. Finally, a single purchaser may be preferred because it may facilitate the coherence and coordination of local health care delivery, which is considered to be important from a public health perspective. The Achilles' heel of the monopsonistic model, however, is the lack of incentives for the third-party purchaser to act as an agent on behalf of the consumers. One may wonder why a monopsonistic third-party purchaser should not enjoy a quiet life. Hence, a system of regulatory incentives and monitoring should be developed to guarantee that the single third-party purchaser will act in the consumers' interest. An option might be to have management teams bidding for franchises which would periodically be recontracted [25].

A strong argument in favour of the competitive model is that competition can provide the purchasers with incentives to act as an effective agent on behalf of their (potential) customers. ${ }^{*}$ However, competition does not automatically generate appropriate incentives. In case of competition among third-party purchasers the key problem is to maintain access and prevent cream skimming, i.e. selection of "profitable" consumers. Therefore, a competitive market of third party purchasing should be complemented with a mechanism to guarantee access and to remove incentives for cream skimming. Although there are technical possibilities to prevent cream skimming [27], a lot of experimentation and evaluation is still needed to assess their feasibility in practice. In a monopsonistic compulsory health insurance market the problem of cream skimming is nonexistent.

Hence, in both competitive and monopsonistic markets for third-party purchasing of health care additional regulation is needed to guarantee that third-party purchasers act in the consumers' interest. However, the nature of the required government intervention in both market types will be quite different. Consequently, in different countries the chosen way of (re)forming the market for third-party purchasing will depend on the possibility to find workable solutions to these problems [5]. The problems related to a competitive market for third-party purchasing may be more severe for countries that formerly had a National Health Service than for insurance-based systems because of a lack of data for the calculation of risk-adjusted capitation payments to the competing third-party purchasers and because of a lack of experience with the regulatory regime for a competitive market of third-party purchasing.

An interesting question is whether in the long run, when these technical problems have been solved, there might occur a convergence, and if so, to what model. According to Enthoven [28], the ideal market

*In this paper I restrict myself to the so-called noncatastrophic risks. For a discussion on catastrophic risks, see [26]. structure would give each medical care organization effective incentives to produce maximum value for money for enrolled subscribers. It should be based on integrated financing and delivery systems--partnerships that link doctors, hospitals and insurers--with per capita prepayment, with providers at risk for costs of care and costs of poor quality, publicly accountable for quality and per capita costs. The ideal market structure must be managed by active, intelligent, collective purchasing agents, called sponsors, that contract with health care systems and set the rules of competition. In Enthoven's ideal model there is competition among accountable health plans. These health plans fulfil the insurance function and must have under contract a panel of providers capable of delivering the full range of covered services.

In practice we may see in different countries all types of mixed models, containing elements of both the competitive model and the monopsonistic model. A good example of a dynamic mixed model is the United Kingdom. When the reforms started in the early 1990s, the monopolistic Regional Health Authorities were the dominant third-party purchasers of care. The number of GP-fundholders, who partly fulfil the role of purchaser of second-line care, was relatively small, and the amount of hospital care that they purchased was only about $15 \%$ of the total costs of hospital care delivered to their patients. However, over time some interesting developments are taking place. First, the number of GP-fundholders steadily increases each year. Second, some GP-fundholders form purchaser coalitions in order to strengthen their position as purchaser and reduce the transaction costs related to contracting; for example, more than 100 fundholding GPs in Birmingham, who serve more than 200,000 patients, work together in Birmingham Multifund. Third, in 1996 a new type of GP-fundholder-besides the traditional GP-fundholder-was introduced: the so-called full-fundholdership. The GP who opts to be a full-fundholder bears, in principle, the financial responsibility for all the follow-up costs of his/her patients. Combination of these new developments, together with the consumer's freedom to choose his GP, might yield a subsystem of the health care sector that consists of competing "multifunds". Via coordinated-care contracts, as discussed in the previous section, the difference between these multifunds and insurers (acting as third-party purchasers of care) or health plans in the competitive model may further diminish. Time will show whether the competitive model or the monopsonistic model will appear to be dominant in the United Kingdom. By the same token, Clause $6 c$ in the New Zealand Health and Disability Services Bill 1992, which allows for the eventual existence of alternative (competing) health care plans as purchasers, may ultimately change the dominant model of the New Zealand health care system. The same holds true for Portugal and Italy, where "opting-out" 
has seriously been discussed. In Israel the consumers have a free choice of sickness funds, which own hospitals and employ physicians. According to Chinitz [29], the Israeli health care has the potential to come close to realizing the conditions for managed competition outlined by Enthoven. Although it is too early to speculate on a convergence to some "ideal model", it is interesting to carefully analyse the similarities (and differences) in health care reform in different countries.

\section{Cost containment}

Cost containment is an important element in the discussion about health care reform. Therefore, an interesting question is: can a competitive health care system be successful in cost containment? Is there any evidence? Because the trend towards competition in health care is still in an initial stage, it is not yet possible to come up with any definite conclusion about the potential success of competition with respect to cost containment. Although managed care plans in the U.S. (HMOs and preferred provider insurance) are able to reduce costs and offer value for money [30-32], they have not helped to slow national health expenditures. According to Enthoven [33], this can be explained because the practices of purchasers (including government and employers), the tax laws, and other market imperfections reduced the demand for cost containment, and thereby deprived managed care plans of an adequate incentive to cut cost and price. According to Enthoven, competition has not yet been tried.

Nevertheless, there are results from some U.S. studies that offer encouragement for advocates of the regulated competition approach. Wholey et al. [34] examined the effects of market structure on $\mathrm{HMO}$ premiums from 1988 to 1991 . They found that more competition, measured by the number of HMOs in the market area, reduces HMO premiums. In an other study Feldstein and Wickizer [35] also found results that support the belief that $\mathrm{HMO}$-induced competition has the potential to control the rate of increase in health care costs. They found that a $10 \%$ increase in the HMO market penetration rate would, on average, lead to a $6.5 \%$ lower annual rate of increase in health insurance premiums. Zwanziger et al. [36] found that the introduction of selective contracting in California in 1982 has reduced the growth rate of hospital costs. Selective contracting had induced hospitals in highly competitive markets to decrease their costs, over the period 1982-1990, by almost $13 \%$ relative to costs at the less competitive hospitals. Some further preliminary results about

*E.g. open entry to the market, well-informed consumers, an adequate anti-cartel policy, transparency of the market and protection of the population against quackery.

$\dagger$ For arguments of whether or not the government should put a global budget on total health care expenditures, see [37]. the effects of competition in health care come from the Netherlands and Sweden. The introduction of selective contracting in the Netherlands in the early 1990s resulted in a reduction of the prices for medical devices by a quarter to a third. The introduction of competitive elements in Sweden ("Stockholm model") resulted in a substantial increase in physicians' productivity.

Although it is too early for definite conclusions about the effect of competition on costs, it is interesting to think about the expected effects of competition. It appears that politicians have expectations about the outcome of a competitive health care market that do not correspond with economic theory. Politicians strongly focus on cost containment in the sense of stabilizing the fraction of gross national product to be spent on health care. Politicians often consider regulated competition in health care as a substitute for detailed government regulation with respect to prices, volume and capacity in order to contain cost. However, economic theory predicts that under certain (ideal) conditions, ${ }^{*}$ competition may improve the efficiency, quality, innovation and responsiveness to consumers' preferences-none of which is synonymous with cost containment in the political sense. Regulated competition can be expected to yield "more value for money". However, if additional health care can contribute to one's health, and if competition in health care yields more value for money, and if most people judge a good health status to be the most important thing in life (more important than a good marriage, housing or job) - as does $60 \%$ of the Dutch population-then we cannot exclude the option that a competitive health care system yields both more efficiency (lower unit costs) and higher total costs (units of higher quality and/or more units).

As a consequence of rising health care expenditures the cross-subsidies that are necessary to guarantee access to care for the sick and low-income earners may also go up. This might ultimately have an adverse effect on the economic process and thereby induce government to put a global budget (or cap) on the public expenditures on health care, i.e. the expenditures which are necessary for the cross-subsidies to the sick and low-income earners. $\dagger$

\section{Choices in health care}

Given the above-indicated trend towards a market-oriented health care and a cap on the public health care expenditures which are necessary for the cross-subsidies to the sick and low-income earners, a crucial question becomes: to what types of health care should the compulsory health insurance provide access? Should everybody have guaranteed access via the compulsory health insurance to all care with any positive benefits, independent of the costs? Can equity be maintained in a competitive health care system? 
In 1991 the Dutch Government Committee on Choices in Health Care advised the government that only care that has been proven to be effective should be included in the benefits package of the mandatory health insurance [38]. All care that has not been proven to be effective, as well as all care that has been proven to be not effective, should not be included in the mandatory insurance benefits package. Further, the Committee advised to exclude those benefits from the compulsory health insurance for which the costs are high and the expected benefits are very low. These excluded types of care are referred to as "cost-ineffective" care. The Committee stressed that it is important to consider the effectiveness of a certain treatment in relation the medical indication and the condition of the patient.

In several lectures about the Committee's report presented by this author to physicians, the question was asked: what percentage of the care that is currently being paid for by the social health insurance system do you think has been proven to be effective? Most estimates of the Dutch physicians ranged between 20 and $40 \%$ and never above $50 \%$. Frequently mentioned examples of ineffective care are: routine laboratory tests, lasting physiotherapy, antibiotics in case of a simple cold caused by a virus, chronic use of sleeping pills, routine physical examinations and lasting psychotherapy. The application of the criterion "effectiveness" would probably substantially reduce the entitlements on benefits covered by the mandatory health insurance. Nevertheless, it is nearly impossible to leave specific services out of the basic benefits package on the basis of the (cost-) effectiveness criterion. The reason is that the effectiveness of care has to be considered in relation to the medical indication and the condition of the patient. Therefore, the Committee places the responsibility for cost-effective care primarily on the professions and their organizations. They must work with others in society in developing the standards for cost-effective care. The medical profession should be active in setting up decision procedures in situations in which the chance of the medical success is low. Areas that could receive attention are, for example, neonatology, chemotherapy for cancer and transplants. Likewise, the professions should set up standards and guidelines for everyday care and use them to assure quality of care. Because vulnerable patients in need of care have a very high willingness to pay to grasp at a straw, the government should protect the population against the marketing of futile care- "your money or your life"-by the medical industry which has an interest, just like any other industry, in enlarging their business. In order to reduce the consumer's demand for futile, low-yield care the population should be well-informed about the low effectiveness of certain medical procedures for specific conditions. The Committee suggested the provision of information in the form of comprehensible information sheets, free telephone lines and the development of choice programmes on common dilemmas, such as whether or not to undergo a prostate operation. The public should be highly involved in defining the basic benefits package. Physicians should explain their patients why a test or intervention in their specific situation is unnecessary. This will increase the patient's understanding and his willingness to give up the idea that "more is better". All these activities should be supported by financial incentives. The Committee is in favour of the introduction of specific economic incentives for the providers such that the use of technology is not more highly rewarded than a consultation with the patient. taking the history, and physical examination. Bonuses and selective contracting could provide complementary incentives to work cost-effectively. Although financial incentives should primarily be addressed to the physicians, they could also be addressed, as discussed previously, to the patients.

Consumer choice of insurance contract. According to the Dutch reform proposal (1988), the insured may choose among several insurance contracts offered by the insurers. All insurance contracts should cover (at least) a standardized basic benefits package. One insurer may offer several insurance contracts as long as the insured's rights are in accordance with the law Besides a so-called "Total Freedom" policy, which reimburses all accounts from all health care providers without any restriction, insurers could also offer so-called "limited provider plans", like HMOs or preferred provider insurance arrangements. Most of the costs would then only be reimbursed when the service is given or prescribed by contracted and carefully selected providers. By specifying quality, volume, price and efficiency of care in the contracts with the providers, insurers could offer cost-effective care. The Government Committee on Choices in Health care advised that insurers should be allowed to refuse to reimburse costs for cost-ineffective care The Committee called such an insurance contract the "Appropriate Care" policy. (There is a clear analogy between such an Appropriate Care policy and the coordinated-care contracts discussed earlier.) The insured would be free to buy, for example, a Total Freedom policy that unconditionally reimburses all health expenditures, but of course the premium of the latter policy would be much higher than that of the former policy. The cross-subsidies to the sick and low-income earners should only be dependent on the health status of the insured, and not on the chosen policy. If there are groups are consumers who prefer to receive care from a certain network of health care providers, the insurers can be expected to respond to these preferences by offering special policies coupled to this network of providers. Thus could the consumers choose one or another insurance contract on the basis of their preferences, their ideas about health care, their lifestyle or beliefs. The insurance contract would be linked on the one hand to the 
conditions on the care to be received (for example: which providers? which facilities? which guidelines?) and on the other hand to the insurance premium. In this way the consumer can make important "choices in health care" through his/her choice of insurance contract.

A difference between the Appropriate Care policy and the Total Freedom policy could be as follows. Suppose there is a certain disease or impairment that can be diagnosed and cured by different methods with different degrees of certainty and different prices: method 1 with $99 \%$ certainty, which costs $\$ 100$, and method 2 with $99.9 \%$ certainty, which costs $\$ 10,000$. The Appropriate Care policy with a relatively low premium would probably cover method 1 and not method 2, while the Total Freedom policy with a very high premium might cover method 2. Another example: suppose in a certain life-threatening situation there exists a treatment with a $1 \%$ chance of success and a price of $\$ 500,000$. The Appropriate Care policy would not cover this treatment because of its low cost-effectiveness, while the Total Freedom policy might cover the treatment (provided that the treatment is not harmful to the patient). The idea of giving the consumer such a choice of insurance contract resembles Pauly's [39] proposal for competition among health plans on the basis of the rate at which new technology is introduced. By offering a choice of insurance contracts, the consumer can make-within a certain range of limits-a choice based on his own preferences with respect to health care, style of care and price. In order to protect the public against a situation where, after developing a serious illness, they regret their choice of insurance contract, each insurance contract should contain at least a specified list of benefits ("merit good" motive).

Equity. Suppose that society makes the explicit choice that method 2 and the $\$ 500,000$ treatment will not be included in the basic benefits package of the mandatory health insurance. The question then arises of whether such a health care system, in which those who can pay will receive method 2 and the $\$ 500,000$ treatment, and those who cannot pay will not receive these treatment, is acceptable for countries where solidarity and equity are high on the political agenda.* In answering this question one has to realize that given a limited amount of money available for the cross-subsidies form the healthy and high-income to the sick and low-income earners, such choices are not only necessary, but also just. Not making such explicit choices will yield an undesired arbitrary two-tier system. It will result in waiting lists and poor quality care in the publicly financed health care sector and prompt services and high-quality élite care in the privately financed sector. Those who can pay will

*If the choice of insurance contract is not related to an individual's purchasing power, the choice of insurance contract reflects a consumer's taste and preferences and need not be a problem. always find their way, abroad or in their own country. For example, in Ireland and in the United Kingdom salaried physicians working in a public hospital are allowed to treat private patients in their private practice for a private fee. Consequently, those who can afford can receive the treatment today, and those who cannot afford have to wait one or two years. The more successful cost containment is, the longer the waiting lists and the more the two-tiered system grows. In several Eastern European countries, formally speaking, health care is "free for all". However, in many cases patients have to make "under the table payments" to the provider. So the total income of salaried physicians often is a multiple of their formal salary. If society considers it unjust that there exists a different access to basic health services for those who have and those who have not, "making explicit choices today" is necessary to "share and share alike tomorrow".

Given a limited amount of money available for the cross-subsidies to the sick and low-income earners, the interpretation of "equity" as "equal access to cost-effective care within a reasonable period of time" seems to be defensible. Nevertheless, this way of thinking is new to a great majority of the population in many developed countries and may be difficult to accept. Until recently, everything that was medically/ technically possible in health care had to be done. However, it should be realized that in other sectors in which health, life and death are at stake, health-promoting factors that are technically possible appear to be economically impossible, because-after weighing costs and benefits--people are not prepared to pay for them. This is seen, for example, in traffic safety (cars, airplanes, level crossings), nuclear power centres, occupational safety and the height of the dikes (a well-known problem in the Netherlands!). The fact that not providing some expensive care to a certain patient may result in an identifiable death, while the future victims of a preventable traffic accident or flood are unknown statistical deaths [40], should not be relevant for decision-making politicians. If the marginal value of the last dollar spent on health care is lower than the marginal value of the last dollar spent on other goods than health care, the application of the cost-effectiveness criterion in health care might improve overall efficiency in society. Those who think it is unfair that low-income earners cannot afford method 2 and the $\$ 500,000$ treatment should realize that other health-influencing matters with probably a larger health effect, like safe cars and good housing (no environmental pollution, no damp, and no noise nuisance), can freely be bought by those who can afford and are willing to pay.

Besides the "inequality" effect of allowing the happy few-if they wish-to buy method 2 and the $\$ 500,000$ treatment, there is also a positive effect. (This argument does not hold if it is the poor few who can not afford). Over time the quality/price ratio of 
these new technologies will probably improve, just as with computers and fax machines, so that after a certain period of time society may decide to include these technologies in the basic benefits package. If Mercedes and Volvo wouldn't have been allowed to firstly implement new safety technologies like ABS and airbags in their luxurious limousines, these technologies wouldn't now be available in a Volkswagen for a reasonable price. By not having blocked dynamic innovation a Volkswagen now is much safer than a Mercedes or Volvo was 30 years ago. Another positive effect is that new medical technologies first have to successfully stand the test of the market. The market will give signals to the industry whether or not new technologies, which are technically feasible, are also economically feasible. If even the highest-income groups do not consider a new technology to be "worthwhile", there is no need to include it in the mandatory basic benefits package.

It is impossible on the basis of the cost-effectiveness criterion to define a mandatory basic benefits package for all societies for all time. Each society has to make its own choices whether or not organ transplants (kidney, heart, lung, and combinations), bone marrow transplants, coronary bypass operations, total parenteral nutrition, magnetic resonance imaging, laser operations of the eye (as a substitute for glasses) and expensive pharmaceuticals (e.g. the beta interferon drug Betaseron, which costs about $\$ 20,000$ per patient per year) are cost-worthy care, and whether the basic package should cover a $\$ 1000$ or $\$ 5000$ heart pacemaker. What can society afford? How large are the altruistic preferences within society? What are the opportunity costs of spending an extra dollar on health care? Each society has to make its own choices and should continuously update them.

\section{CONCLUSION AND DISCUSSION}

In this paper we have indicated some international trends in health care reforms and explored some potential future options. From an international perspective we can observe a trend towards universal mandatory health insurance, contracts between third-party purchasers and the providers of care, competition among providers of care and a strengthening of primary care. These trends can be expected to continue. A more controversial issue is whether there should also be competition among the third-party purchasers and whether in the long run there will occur a convergence towards some "ideal" model. The introduction of market-oriented elements (incentives, regulated competition) in health care has the advantage that it allows to break through the vicious circle of ever-increasing health care expenditures. In many health care systems there are more cost-increasing than cost-decreasing incentives. The medical industry has an interest in enlarging their business, physicians are often paid a fee for service (also for unnecessary care and for unnecessarily expensive care), third-party purchasers often have no interest in cost containment, and the consumer has zero or low marginal out-of-pocket payments because of health insurance. So there often exists a strong coalition in the health care sector with no interest in cost containment. Via market elements all parties can be given any interest, at different levels, in making a trade-off between costs and quality.

However, although regulated competition in health care can be expected to yield more value for money, it cannot guarantee that health care expenditures will not further rise, or even go down. We cannot exclude the option that a competitive health care system yields both more efficiency and higher total costs. An important question, therefore, is: can equity be maintained in a competitive health care system? It has been argued that this can be done if we interpret equity as "equal access to cost-effective care within a reasonable period of time".

Because the effectiveness of care has to be considered in relation to the medical indication and the condition of the patient, the responsibility for cost-effective care rests primarily with the providers of care. Guidelines and protocols should be developed by the profession and sustained by financial incentives embedded in contracts.

It has been argued that the third-party purchasers could start to concentrate on the contracts with the primary care physicians. Contracts with other providers (specialist care and institutional care) could then be a natural complement to these contracts and could in fact be supportive to the conditions agreed upon in the contracts between the purchaser and the primary care physicians. Coordinated-care contracts between the third-party purchasers and the consumer of care could provide the consumer with monetary incentives to go to efficient providers.

A consumer choice of insurance contract could give the consumer an opportunity to make important choices in health care through his/her choice of insurance contract. However, each society has to make its own choices about what care should be available to everybody independent of an individual's purchasing power.

\section{REFERENCES}

1. The Reform of Health Care Systems: A Comparative Analysis of Seven OECD Countries, Health Policy Studies No. 2. OECD, Paris, 1992.

2. The Reform of Health Care Systems: A Review of Seventeen $O E C D$ Countries, Health Policy Studies No. 5. OECD, Paris, 1994.

3. Abel-Smith B. and Mossialos E. (1994) Cost containment and health care reform: a study of the European Union. Health Policy 28, 89.

4. Ham C. and Brommels M. (1994) Health care reform in the Netherlands, Sweden and the United Kingdom. Health Affairs 13(5), 106. 
5. van de Ven W. P. M. M., Schut F. T. and Rutten F. F. H. (1994) Forming and reforming the market for third-party purchasing of health care. Social Science \& Medicine 39, 1405.

6. Saltman R. and von Otter C. Planned Markets and Public Competition. Open University Press, Buckingham, 1992.

7. Hillman A. L. (1987) Financial incentives for physicians in HMOs. Is there a conflict of interest? New England Journal of Medicine 317, 1743.

8. Kitzhaber J. and Kenny A. M. (1995) On the Oregon trail. British Medical Bulletin 51, 808.

9. van de Ven W. P. M. M. (1995) Choices in health care: a contribution form the Netherlands. British Medical Bulletin 51, 781 .

10. Cooper M. H. (1995) Core services and the New Zealand health reforms. British Medical Bulletin 51, 799.

11. Calltrop J. (1995) Sweden: no easy choices. British Medical Bulletin 51, 791.

12. Klein R. P. and Redmayne S. (1995) Rationing in the NHS: the dance of the seven vails-in reverse. British Medical Bulletin 51, 769.

13. Wennberg J. E. (1987) The paradox of appropriate care. Journal of American Medical Association 258, 2568.

14. Mokkink H. G. A. Ziekenfondscijfers als Parameter voor het handelen van Huisartsen, Dissertation. University of Nijmegen, 1986.

15. Roper W. L., Winkenwerder W., Hackbarth G. M. and Krakauer H. (1988) Effectiveness in health care: an initiative to evaluate and improve medical practice. New England Journal of Medicine 319, 1197.

16. Wennberg J. E., Blowers L., Parker R. and Gittelsohn A. M. (1977) Changes in tonsillectomy rates associated with feedback and review. Pediatrics 59, 821 .

17. Dyck F. J. et al. (1977) Effects of surveillance on the number of hysterectomies in the province of Saskatchewan. New England Journal of Medicine 296, 1326.

18. Lomas J. et al. (1989) Do practise guidelines guide practice? New England Journal of Medicine 321, 1306.

19. Gornick M., Lubitz J. and Riley G. (1991) U.S. initiatives and approaches for outcomes and effectiveness research. Health Policy 17, 209.

20. Krasnik A. et al. (1990) Changing remuneration systems: effects on activety in general practise. British Medical Journal 300, 1698.

21. Hemenway D., Killen A., Cashman S. B., Parks C. L. and Bicknell W. J. (1990) Physicians' responses to financial incentives. New England Journal of Medicine 322, 1059.

22. Hillman A. L., Pauly M. V. and Kerstein J. J. (1989) How do financial incentives affects physicians' clinical decisions and the financial performance of health maintenance organizations? New England Journal of Medicine 321, 86.
23. Van Tits M. H. and Nuyens W. J. F. I. The impact of financial incentives on the behavior of general practitioners; and experiment, Paper presented at the Second World Congress on Health Economics, Zürich, 1990.

24. Enthoven A. C. Management information and analysis for the Swedish health care system, Working paper no. 7. Swedish Institute for Health Economics, 1989.

25. Cuyler A., and Posnett J. Hospital behaviour and competition. In Competition in Health Care (Edited by Cuyler A., Maynard A. and Posnett J.), pp. 12-47. MacMillan, London, 1990.

26. van de Ven W. P. M. M. and Schut F. T. (1994) Should catastrophic risks be included in a competitive health insurance market? Social Science and Medicine 39, 1459.

27. van de Ven W. P. M. M., van Vliet R. C. J. A., van Barneveld E. M. and Lamers L. M. (1994) Risk-adjusted capitation: recent experiences in the Netherlands. Health Affairs 13, 120.

28. Enthoven A. C. (1994) On the ideal market structure for third-party purchasing of health care. Social Science \& Medicine 39, 1413.

29. Chinitz D. P. (1994) Reforming the Israeli health care market. Social Science and Medicine 39, 1447.

30. Luft H. S. Health Maintenance Organizations: Dimensions of Performance. John Wiley, New York, 1981.

31. Manning W. G., Leibowitz A., Goldberger G. A., Rogers W. H. and Newhouse J. P. (1984) A controlled trial of the effect of a prepaid group practice on use of services. New England Journal of Medicine 310, 1505.

32. Miller R. H. and Luft H. S. (1994) Managed care plan performance since 1980: a literature analysis. JAMA 271, 1512.

33. Enthoven A. C. (1993) Why managed care has failed to contain health costs. Health Affairs 12, 27.

34. Wholey D., Feldman R. and Christianson J. B. (1995) The effect of market structure on HMO premiums. Journal of Health Economics 14, 81.

35. Feldstein P. J. and Wickizer T. M. (1995) Analysis of private health insurance premium growth rates: 1985-1992. Medical Care 33, 1035.

36. Zwanziger J., Melnick G. A. and Bamezai A. (1994) Cost and price competition in California hospitals, 1980-1990. Health Affairs 13, 118.

37. van de Ven W. P. M. M. (1995) Regulated competition in health care: with or without a global budget? European Economic Review 39, 786.

38. Government Committee on Choices in Health Care Choices in Health Care. Ministry of Welfare, Health and Cultural Affairs, the Netherlands, 1991.

39. Pauly M. V. (1990) Financing health care. Quarterly Review of Economics and Business 30, 63.

40. Keeney R. L. (1994) Decisions about life-threatening risks. New England Journal of Medicine 331, 193. 